\title{
Estrogen receptor alpha gene polymorphisms and risk of HBV-related acute liver failure in the Chinese population
}

\author{
Zehui Yan', Wenting Tan ${ }^{1}$, Yunjie Dan ${ }^{1}$, Wenli Zhao ${ }^{1}$, Chunqing Deng ${ }^{1}$, Yuming Wang ${ }^{1 *}$ and Guohong Deng ${ }^{1,2^{*}}$
}

\begin{abstract}
Background: The sexual dimorphism of hepatitis B virus (HBV) -related liver diseases is related with estrogen and its receptors. Recent reports indicate that abnormal expression of estrogen receptor alpha (ESR1) may be a hallmark for the progression of liver disease and HBV carriers presenting variant ESR1 have an extremely aggressive clinical course. Here we examine whether the ESR1 polymorphisms or its haplotypes are related to HBV-related acute liver failure (ALF) risk among chronic HBV carriers in a Chinese population.

Methods: A total of 1216 unrelated Han Chinese HBV carriers were recruited in this hospital-based case-control study, including 359 HBV surface antigen (HBsAg) carriers affected with ALF and 857 asymptomatic HBsAg carriers. Two ESR1 haplotype tagging polymorphisms, C.30 T > C (rs2077647) and c.453-397 T > C (rs2234693), were genotyped by polymerase chain reaction-restriction fragment length polymorphism (PCR-RFLP) assay.

Results: We observed a significantly increased susceptibility to HBV-ALF associated with the c.30 C allele $\left(\mathrm{P}=8.65 \times 10^{-4}\right), c .453-397 \mathrm{C}$ allele $\left(5.37 \times 10^{-4}\right)$ and $[\mathrm{c} .30 \mathrm{C} ; \mathrm{c} .453-397 \mathrm{C}$ ] haplotype (Dominant model, $P=0.0004$, odds ratio $=1.53,95 \% \mathrm{Cl} 1.23 \sim 1.96$ ) compared with the T alleles and [C.30 T; c.453-397 T] haplotype of c.30 T > C and c.453-397 T>C polymorphisms, respectively.

Conclusions: Our study suggests that [c.30 C; c.453-397 C] hapotype may be a risk factor for genetic susceptibility to HBV-related ALF in the Chinese population. It also emphasizes the importance of ESR1 in the pathophysiology of HBV-related ALF on the population level.
\end{abstract}

\section{Background}

Acute liver failure (ALF) is a condition in which rapid deterioration of liver function results in altered mentation and coagulopathy in previously normal individuals. The most widely accepted definition of ALF includes evidence of coagulation abnormality, usually an INR $\geq$ 1.5 , and any degree of mental alteration (encephalopathy) in a patient without preexisting cirrhosis and with an illness of $<26$ weeks duration [1]. ALF is the final common pathway of severe hepatocyte injury. The etiology of ALF shows worldwide variation, prominent causes include drug-induced liver injury, viral hepatitis,

\footnotetext{
*Correspondence: wym417@163.com; ghdengsnp@hotmail.com

${ }^{1}$ Institute of Infectious Diseases, Southwest Hospital Third Military Medical

University, Chongqing 400038, P. R. China

${ }^{2}$ Institute of Immunology Third Military Medical University, Chongqing 400038,

P. R. China

Full list of author information is available at the end of the article
}

autoimmune liver disease and shock or hypoperfusion. Unlike western countries, ALF is one of the end-staged liver diseases caused mainly by hepatitis B virus (HBV) infection (at least 60\%) in China [2]. However, regardless of etiology, chronic hepatitis B progresses at unequal rates between males and females, being more frequent in men than in women [3]. This sexual dimorphism and the greater progression to the end-staged liver diseases in men and postmenopausal women may be due, at least in part, to lower production of estrogen and a reduced response to the action of estrogen [4].

Estrogen is a potent endogenous antioxidant which attenuates induction of redox sensitive transcription factors and hepatocyte apoptosis by inhibiting generation of reactive oxygen species [5]. The effects of estrogens are mediated by estrogen receptors (ESRs). When estrogen binds to its receptor, it would activate and regulate 
multiplegenes, such as activator protein-1, B-cell lymphoma 2, nuclear factor $\kappa B$, tumor necrosis factor $\alpha$ and interleukin-6 [6-8]. There are two known ESRs: estrogen receptor $\alpha$ (ESR1) and estrogen receptor $\beta$ (ESR2). The majority of the biological effects of estrogen are mediated by ESR1 in the liver [9]. ESR1 has been well characterized in human liver [10], hepatic cytosolic ESR1 content was detected on the progression of chronic liver disease [11-13]. The abnormal ESR1 expressions in the liver have been implicated in stimulating hepatocyte injury and may act as liver disease inducers or promoters [14]. Furthermore, variant ESR1 is expressed to a greater extent in male patients than in females, even at an early stage of chronic liver disease $[15,16]$. Therefore, variant ESR1 may be a hallmark for the progression of liver disease and HBV carriers presenting variant ESRa1 have an extremely aggressive clinical course [17].

Investigators have also hypothesized the ESR1 (NM_000125.3) genetic variants may influence an individual's estrogen-sensitive phenotypes [18]. We have screened single nucleotide polymorphisms (SNPs) systematically in the ESR1 gene and two linkage disequilibrium (LD) blocks covering the ESR1 gene were identified [19]. Two polymorphisms, ESR1 c.30 T >C (rs2077647, previously reported T29C, exon 1) and c.453-397 T $>\mathrm{C}$ (rs2234693, previously reported IVS1 T-401 C, intron 1), which were identified as haplotype tagging SNPs, influence the susceptibility to persistent HBV infection [19], HBV-related liver cirrhosis [20] and hepatocellular carcinoma [21]. We also observed that the relative mRNA levels of the risk c. $30 \mathrm{C}$ allele were consistently higher than those of the c.30 T allele in c. $30 \mathrm{~T}>\mathrm{C}$ heterozygotes [21]. Functional analyses also showed that the c.453-397 T $>\mathrm{C}$ polymorphism is a novel c.453-397 $\mathrm{C}$ allele-specific and c-myb-dependent enhancer-like cis-acting regulatory variation and could be part of the genetic variations underlying the susceptibility of individuals to HBV-related diseases [20].

Host genetic polymorphisms may involve the the pathophysiology of HBV-ALF. We have reported that the $-592 \mathrm{C}$ allele and the -1082A-819 C-592 C haplotype in the $I L-10$ gene promoter were associated with an increased susceptibility to ALF in HBV carriers [22]. In this study, we hypotheses that ESR1 may be another appropriated biological candidate susceptibility gene for HBV-ALF. It is expected that the ESR1 genetic variation could influence the effects of estrogens, which in turn results in genotype-dependent differences in risk of HBV-ALF. Therefore, we selected the two haplotype tagging SNPs (c.30 T >C and c.453-397 T $>$ C) from previously association LD block of ESR1 and examined their relationships with the susceptibility to HBV-ALF in a large sample of case-control cohort.

\section{Methods}

\section{Study participants}

Hospital-based case-control study was conducted at Southwest Hospital (Chongqing, China) between February 2001 and December 2009. A total of 1216 unrelated Han Chinese HBV carriers were recruited, including 359 HBV surface antigen (HBsAg) carriers affected with ALF and 857 asymptomatic HBsAg carriers. All HBsAg carriers were positive for both HBsAg and antibody to HBV core antigen (anti-HBc) of the IgG type for at least 12 months. All carriers were measured with liver function tests, serum immunologic marker screening, at least one liver image examination (Ultrasonography, Computed Tomography, Magnetic Resonance Imaging and Fibroscan), and 113 (9.3\%) were examined with histological biopsy. All carriers had no serologic evidence for coinfection or superinfection with hepatitis A virus, hepatitis $C$ virus, hepatitis D virus, hepatitis $\mathrm{E}$ virus, and human immunodeficiency virus.

ALF was defined as liver failure with jaundice, coagulation abnormality (usually an INR $\geq 1.5$ ), and any degree of mental alteration (encephalopathy) in a patient with an illness of less than 26 weeks duration. All patients with ALF had no evidence with preexisting cirrhosis. Information on acetaminophen and idiosyncratic drug and treatment history of these patients was obtained mainly from clinical records and short telephone interviews when necessary. The carriers, who had history of acetaminophen overdose and idiosyncratic drug reactions, were excluded from the HBV-ALF group. Asymptomatic HBV carriers were diagnosed according to the following criteria: (1) lack of any clinical symptoms; (2) normal liver enzyme tests; (3) normal peripheral blood leucocyte $\left(4 \sim 10 \times 10^{9} / \mathrm{L}\right)$ and platelet $\left(100 \sim 400 \times 10^{9} / \mathrm{L}\right)$ counts; (4) serum albumin $>39 \mathrm{~g} / \mathrm{L}$, globulin $<35 \mathrm{~g} / \mathrm{L}$, and the ratio of albumin to globulin (A/G) $>1.5$; (5) normal prothrombin time and serum total bilirubin; (6) no abnormal findings on abdominal ultrasound scans; (7) no esophageal varix revealed by electronic gastroscopy. The examininations or tests were performed once every 6 months from February 2001 to December 2007. The carriers, who occurred to the hepatitis symptoms or cirrhosis evidences during the follow-up, were also excluded from the ASC group.

Further clinical and demographic characteristics of the studied population are shown in Table 1. All subjects provided informed consent to participate in the study, as approved by the ethical committee of Southwest Hospital, Chongqing, China.

\section{DNA extraction and genotyping}

Genomic DNA was extracted from peripheral blood leukocytes from $5 \mathrm{~mL}$ whole blood by using standard phenol/chloroform protocols. DNA samples were diluted 
Table 1 Distribution of Selected Characteristics and ESR1 Polymorphisms in Participants

\begin{tabular}{|c|c|c|c|}
\hline \multirow[t]{2}{*}{ Characteristic } & \multirow{2}{*}{$\frac{\text { ASC }}{(n=857)}$} & \multirow{2}{*}{$\begin{array}{l}\text { HBV-ALF } \\
(n=359)\end{array}$} & \multirow[t]{2}{*}{$P$ value } \\
\hline & & & \\
\hline \multicolumn{4}{|l|}{ Gender, no. (\%) } \\
\hline Men & $510(59.5)$ & $298(83.0)$ & \\
\hline Women & $347(40.5)$ & $61(17.0)$ & $<0.001$ \\
\hline Age (years), mean (SD) & $36.6 \pm 11.3$ & $41.1 \pm 12.7$ & $<0.001$ \\
\hline Alcohol drinkers, no. (\%) & $160(18.7)$ & $121(33.7)$ & $<0.001$ \\
\hline HBeAg positive, no (\%) & 298(34.8) & 107(29.8) & 0.094 \\
\hline TBil $(\mu \mathrm{mol} / \mathrm{L})$ & $13.4 \pm 4.3$ & $321.1 \pm 166.1$ & \\
\hline ALT (IU/L) & $27.9 \pm 10.7$ & $410.1 \pm 541.6$ & \\
\hline \multicolumn{4}{|l|}{ c.453-397 T > C (rs2234693) } \\
\hline Tा, no. (\%) & $330(38.4)$ & 109(30.4) & \\
\hline TC, no. (\%) & $424(49.6)$ & $182(50.7)$ & \\
\hline CC, no. (\%) & $103(12.0)$ & $68(18.9)$ & \\
\hline T allele, no. (\%) & $1086(62.4)$ & $400(55.7)$ & \\
\hline C allele, no. (\%) & 632(36.9) & $318(44.3)$ & $5.37 \times 10^{-4}$ \\
\hline \multicolumn{4}{|l|}{ c.30 T > C (rs2077647) } \\
\hline T, no. (\%) & 418(48.8) & 143 (39.8) & \\
\hline TC, no. (\%) & $348(40.6)$ & $160(44.7)$ & \\
\hline CC, no. (\%) & $91(10.6)$ & $56(15.6)$ & \\
\hline T allele, no. (\%) & $1184(69.1)$ & $446(62.1)$ & \\
\hline C allele, no. (\%) & $530(30.9)$ & $272(37.9)$ & $8.65 \times 10^{-4}$ \\
\hline
\end{tabular}

Notes: "Drinker" was defined as alcohol consumption of $\geq 40 \mathrm{~g} /$ week for men and $\geq 20 \mathrm{~g} /$ week for women, which included occasional drinkers and daily drinkers. The genotype distributions of SNPs in each group were in HardyWeinberg equilibrium. $P$ values were given for the comparison between ASC and HBV-ALF groups by $X^{2}$ tests. TBil, total bilirubin; ASC, asymptomatic HBV carriers; $H B V-A L F$, patients with $\mathrm{HBV}$-related acute liver failure.

to10 $\mathrm{ng} / \mu \mathrm{L}$ and distributed into 96-well plates (DNA panels), with 94 samples and 2 controls (DNA-free water) in each plate. Entrez nucleotide database (http// ncbi.nlm.nih.gov) NT_025741.15:g and dbSNP ID were used as the reference sequences for ESR1 genomic and cDNA sequences. DNA sequence variations are named according to the nomenclature recommendations from http://www.hgvs.org/mutnomen/recs-DNA.html [23,24]. The ESR1 c.30 $\mathrm{T}>\mathrm{C}$ and c.453-397 $\mathrm{T}>\mathrm{C}$ polymorphisms were genotyped by polymerase chain reactionrestriction fragment length polymorphism (PCR-RFLP) analysis in our case-control population.

For the c.30 $\mathrm{T}>\mathrm{C}$ polymorphism, an amplification using the forward primer 5'-GACCATGACCCTCCA CACCAAAGGATC $-3(\underline{G}$, mismatch base) and reverse primer 5' - A $\bar{C} C G T A G A C C T G C G C G T T G$-3' was performed at an annealing temperature of $61{ }^{\circ} \mathrm{C}$. The reaction yielded a $220 \mathrm{bp}$ amplicon. A BamH I recognition site was introduced by 1-base mismatch (underlined base) in the forward primer. Three microliters PCR products were digested with $4 \mathrm{U}$ BamH I (Toyobo, Japan). Digested amplicons from the homozygotes for c.30 C allele appeared as 197-bp and 23-bp bands on the agarose gel electrophoresis, while homozygotes for c.30 T allele appeared as a 220-bp band. Heterozygotes of c.30TC had all 3 of these bands.

For the c.453-397 $\mathrm{T}>\mathrm{C}$ polymorphism, amplification using the forward primer 5'-CATGAACCACCATGCT CAGTC-3' and reverse primer 5'-ACTCTCTGGGA GATGCAGCAG-3' was performed at an annealing temperature of $63{ }^{\circ} \mathrm{C}$. The reaction yielded a $548 \mathrm{bp}$ amplicon. Three microliters PCR products were digested with $4 \mathrm{U}$ PvuII (Toyobo, Japan), and separated on 3\% agarose gel and stained with ethidium bromide for visualization under UV light. Digested amplicons from the homozygotes for c.453-397 T allele appeared as 346bp and 202-bp bands on the agarose gel electrophoresis, while homozygotes for c.453-397 C allele appeared as a 548-bp band. Heterozygotes of c.453-397TC had all 3 of these bands.

Genotyping was performed in a blind manner without information of subjects' case/control status. The accuracy of genotyping data for SNP obtained from PCRRFLP was validated by direct sequencing of 90 masked, random samples of patients.

\section{Haplotype construction and statistical analysis}

Allele frequencies for each SNP were determined by gene counting, and the significance of deviations from Hardy-Weinberg equilibrium was tested using the random-permutation procedure implemented in the Arlequin package (http://lgb.unige.ch/arlequin/). ESR1 haplotypes were assigned by the PHASE program [25]. Pair-wise linkage disequilibrium (LD) between SNPs was analyzed by LDA [26].

Statistical analysis was performed using SPSS software (version 9.0; SPSS Inc, Chicago, IL). A p-value less than 0.05 was considered significant. $X^{2}$ tests were performed to examine the differences in the allele frequency and genotype distribution between groups. Multivariable logistic regression analysis was performed to adjust risk factors such as age, sex, and alcohol use. The association between genotyped polymorphisms and the risk of disease was estimated by $P$ values, odds ratios (ORs), and 95\% confidence intervals (95\% CIs).

\section{Results}

The selected characteristics and genotype distributions of the ESR1 c.30 $\mathrm{T}>\mathrm{C}$ and c.453-397 $\mathrm{T}>\mathrm{C}$ polymorphisms in ASCs and HBV-ALF groups are summarized in Table 1. Although efforts were made to obtain good matches on age and sex between ASCs and HBVALF groups, HBV-ALF groups were older and consisted more men $(\mathrm{P}<0.001)$. The difference in the alcohol consumption status between the ASCs and HBV-ALF groups $(\mathrm{P}<0.001)$ was observed, which may due to 
gender difference since few women drink in China. There was no significant difference with the percentage of $\mathrm{HBeAg}$ positive $(\mathrm{P}=0.094)$ between the asymptomatic HBV carriers (34.8\%) and the patients of HBVrelated ALF (29.8\%). The genotype distributions for the two SNPs were in Hardy-Weinberg equilibrium in each group. The c.30 $\mathrm{T}>\mathrm{C}$ and c.453-397 $\mathrm{T}>\mathrm{C}$ polymorphisms were in linkage disequilibrium with each other $\left(D^{\prime}=0.796, r^{2}=0.538, Q\right.$ value $\left.=0.951\right)$. The $c .30 \mathrm{C}$ and c.453-39 $\mathrm{C}$ allele frequencies were significantly higher in HBV-ALF patients than those in ASCs $(P<0.05)$. Subjects bearing at least one c.453-39 C and c.30 C alleles had an increased susceptibility to HBV-related ALF compared with those without c.453-39 $\mathrm{C}$ and c.30 C alleles (c.453-397 T $>C, P=5.37 \times 10^{-4}$; T29C, $P=8.65 \times 10^{-4}$ ) in our case-control sample.

To decrease the bias of age and sex on the effect estimates, we conducted stratification analysis for age and sex in total 1216 case and control individuals (Table 2). The association between two haplotype tagging SNPs (c.30 T $>$ C and c.453-397 $\mathrm{T}>\mathrm{C}$ ) and HBV-ALF remained significant in male patients (c.453-397 $\mathrm{T}>\mathrm{C}$, $P=0.005$; c. $30 \mathrm{~T}>\mathrm{C}, P=0.022$ ), female patients(c.453$397 \mathrm{~T}>\mathrm{C}, P=0.033$; c.30 T $>C, P=0.021$ ), patients with age $\geq 40$ years (c.453-397 T $>C, P=0.005 ;$ c. $30 \mathrm{~T}>\mathrm{C}$, $P=0.0003$ ), and patients with age $<40$ years (c.453$397 \mathrm{~T}>\mathrm{C}, P=0.011$; c.30 T $>\mathrm{C}, P=0.003)$. As table 2 showed, the logistic regression analysis with adjustment for covariates, including age, sex, $\mathrm{HBeAg}$ status and alcohol consumption also suggested that the genotype effects of these two SNPs were significantly associated with the risk to HBV-ALF in both gender and patients at any age (with an age $\geq 40$ years or $<40$ years).

Haplotypes based on the c.30 T $>$ C and c.453-397 T > $\mathrm{C}$ polymorphisms were constructed to derive haplotypes specifically correlated with HBV-ALF. Four haplotypes, $[\mathrm{T} ; \mathrm{T}],[\mathrm{T} ; \mathrm{C}],[\mathrm{C} ; \mathrm{T}]$, and $[\mathrm{C} ; \mathrm{C}]$, were observed, and two haplotypes, $[\mathrm{T} ; \mathrm{T}]$ and $[\mathrm{C} ; \mathrm{C}]$, had frequencies more than $10 \%$. The estimated haplotype distribution differed significantly between the ASCs and HBV-ALF groups

Table 2 Stratification Analysis of Age and Gender on Association between ESR1 C.30 T $>$ C \& c.453-397 T > Genotypes and Different Groups

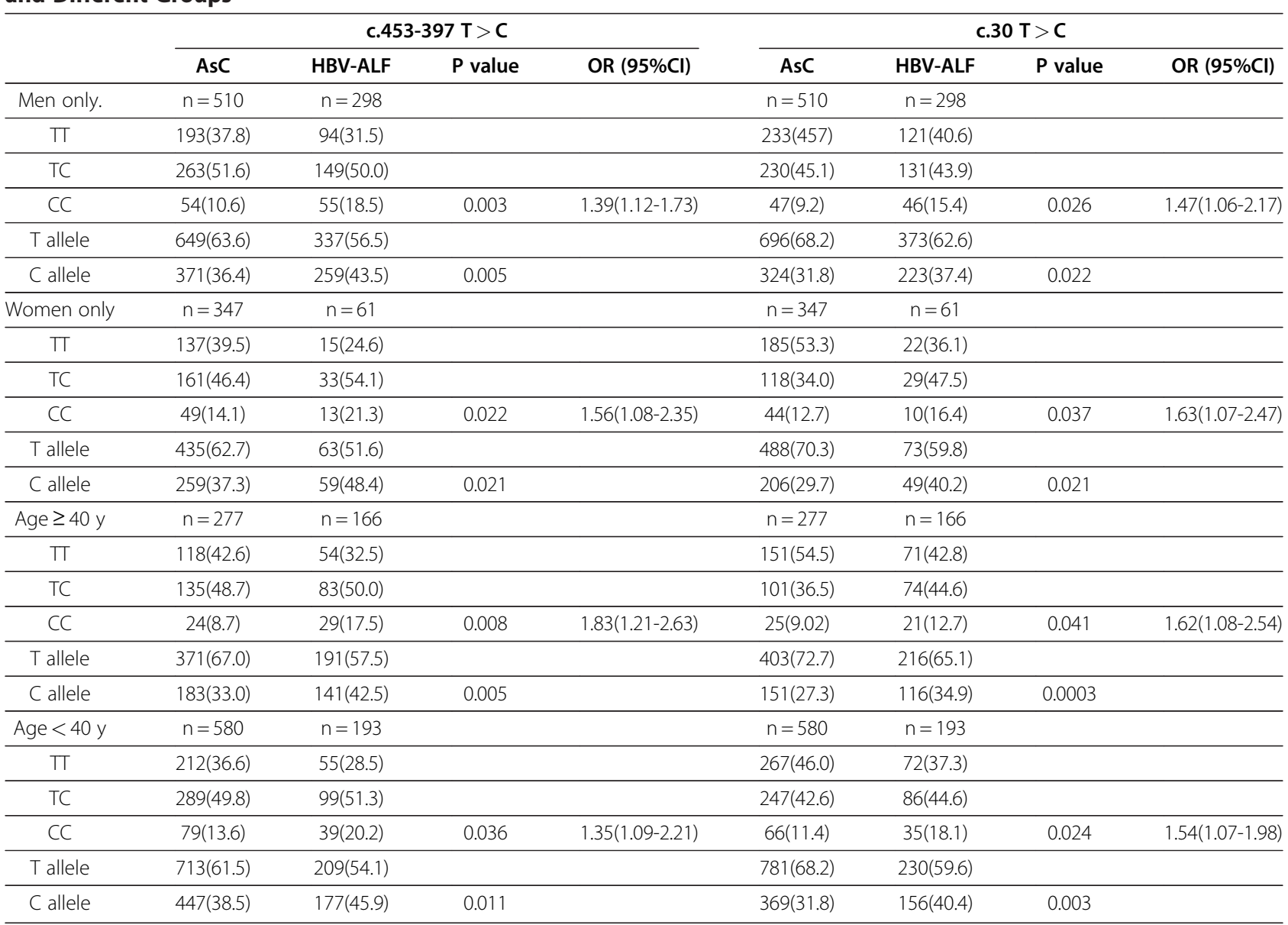

Notes: $P$ values were given for the comparison of the allele effect between ASC and HBV-ALF groups by $X^{2}$ tests. Odds ratios (OR) and their $95 \%$ confidence interval $(95 \% \mathrm{Cl})$ were given for the comparison of the genotype effect between ASC and HBV-ALF groups by logistic regression analysis with adjustment for covariates, including age, sex, HBeAg status and alcohol consumption. ASC, asymptomatic HBV carriers; HBV- ALF, patients with HBV-related acute liver failure. 
$\left(\chi^{2}=19.74, P=0.0002\right.$, Table 3). The frequency of [T; T] haplotype decreased significantly in the HBV-ALF group, as compared to ASCs. We categorized the ESR1 haplotypes into three groups, i.e., ' $[\mathrm{T} ; \mathrm{T}] /[\mathrm{T} ; \mathrm{T}]$ ' homozygotes, '[T; T]]/[-,-]' heterozygotes, and '[-;-]/[-;-]' homozygotes ('[-;-]'means non-[T; T] haplotypes, Table 3). Logistic regression analysis with adjustment for age, sex, HBeAg status and alcohol consumption indicated significant differences in the distribution of the three haplotype groups between the ASC and HBV-ALF groups. Non-[T; T]] ('[-;-]/[-;-]') haplotypes had a significantly increased risk to HBV-ALF (Dominant model, $P=0.0004$, odds ratio $=$ $1.53,95 \%$ CI $1.23 \sim 1.96)$.

\section{Discussion}

In our case-control association study, we observed an increased risk of HBV-ALF in patients who carry ESR1 c.30 C, c.453-397 C allele and [c.30 C; c.453-397 C] haplotype. This risk estimates did not change after adjustment for gender, age and alcohol consumption status, indicated that ESR1 c.30 C, c.453-397 C allele and [c.30 C; c.453-397 C] haplotype is an independent risk factor. Combined with the novel evidences that the c.453-397 $\mathrm{T}>\mathrm{C}$ polymorphism is a novel c.453-397 C allele-specific and c-myb-dependent enhancer-like cisacting regulatory variation [20], our study emphasizes the importance of ESR1 in the pathophysiology of HBVALF on the population level. To our knowledge, this is the first report that the functional polymorphisms of ESR1gene may determine an individual's susceptibility to HBV-ALF.

The design and results of our study manifest the features that are considered desirable components of an ideal association study [27]. These characteristics include

Table 3 Results of the Association Test for ESR1 Haplotypes between ASC and HBV-related ALF Groups

\begin{tabular}{|c|c|c|c|c|}
\hline \multirow[t]{2}{*}{ Characteristic } & \multirow{2}{*}{$\frac{A s C}{(2 n=1714)}$} & \multirow{2}{*}{$\frac{\text { HBV-ALF }}{(2 n=690)}$} & \multirow[t]{2}{*}{$P$ value } & \multirow[t]{2}{*}{ OR $(95 \% \mathrm{Cl})$} \\
\hline & & & & \\
\hline \multicolumn{5}{|c|}{ Haplotype, no. (\%) } \\
\hline$[T ; T]$ & $1023(59.7)$ & $365(50.8)$ & & \\
\hline$[T ; C]$ & $142(8.3)$ & $82(11.5)$ & & \\
\hline$[C ; T]$ & $54(3.1)$ & $36(5.0)$ & & \\
\hline$[\mathrm{C} ; \mathrm{C}]$ & 495(28.9) & $235(32.7)$ & & \\
\hline Total $(3 d f) \S$ & & & 0.0002 & \\
\hline
\end{tabular}

Haplotype groups, no. (\%)

\begin{tabular}{rrrrr}
\hline$\Pi ; T] /[;\rceil]$ & $294(34.3)$ & $97(27.1)$ & & \\
\hline$\Pi ; T] /[-;]$ & $435(50.8)$ & $171(47.6)$ & & \\
\hline$[-;-] /[-;]$ & $128(14.9)$ & $91(25.3)$ & 0.0004 & $1.53(1.23 \sim 1.96)$ \\
\hline
\end{tabular}

Notes: $\S$ For haplotype, $P$ values were given by $2 \times 4$ table chi-square; '[-;-]' means any other haplotypes; $O R=$ odds ratio; $C l=$ confidence interval; the association was analyzed by logistic regression analysis with adjustment for covariates, including age, sex, and alcohol consumption. AsC, asymptomatic carriers; $H B V$ - $A L F$, patients with $H B V$-related acute liver failure. a large cohort size, rigorous phenotypic selection, independent sample validation, plausible biological context, low $P$ values, and appropriate statistical and $L D$ test. Most HBV carriers are infected by maternal-infantile transmission in China. Both ALF cases and controls are HBV carriers in this study, which ensure all the subjects in the study having the history of HBV exposure, the association of ESR1 polymorphisms with ALF may not due to population bias. To decrease the bias of age and sex on the effect of the estimate, we conducted stratification analysis for age and sex. Interestingly the association between the two ESR1 polymorphisms (c.453-397 T > C and c.30 $\mathrm{T}>\mathrm{C}$ ) and HBV-ALF remained significant in both sex and patients at any age (with an age $\geq 40$ years or $<40$ years). The $\mathrm{P}$ value for the whole case control comparison is at the $10^{-4}$ level. According to the Better Associations for Disease and Genes (BADGE) system for describing genetic associations proposed by Manly [28] and the criteria proposed by Wacholder et al. [29], the false positive report probability (FPRP) of our results is very low. Although the highly significant association between ESR1 polymorphisms and susceptibility to HBVrelated ALF derives from biologically based a priori hypothesis, our initial findings should be independently verified in populations of different ancestry, especially in other East Asia populations, where HBV infection is the major cause of ALF. Furthermore, it is reasonable to speculate that the effects of the two SNPs on the occurrence of ALF may be different between postmenopausal and premenopausal women. Then, it will be better to conduct a stratification analysis for menopausal status in total HBV-ALF women. However, the number of potential postmenopausal women $(\mathrm{N}=27)$ and premenopausal women $(\mathrm{N}=34)$ in the HBV-ALF group is too small to gain enough statistical. In the following study, the expanded numbers of women patients with HBV-ALF will be help clarify the effects of the two SNPs on the occurrence of ALF between postmenopausal and premenopausal women.

It is conceivable that the common sequence variations in the ESR1 gene affect the risk of different disease phenotype, such as breast cancer [30,31], osteoarthritis [32], cardiovascular disease [33], and migraine [34]. Our study group also has found that the ESR1 polymorphisms influenced the susceptibility to persistent HBV infection [19], HBV-related liver cirrhosis [20] and hepatocellular carcinoma [21] and showed that the c.453-397 $\mathrm{T}>\mathrm{C}$ polymorphism is a novel c.453-397 C allele-specific and c-myb-dependent enhancer-like cisacting regulatory variation and could be part of the genetic variations underlying the susceptibility of individuals to HBV-related diseases [20]. The consistency of functional consequences is an additional strong point of our genetic epidemiological investigation. 
Estrogen and variant ESR1 participates in the pathogenesis of HBV-related liver diseases [17,35]. During the course of chronic hepatitis B progressing to end-stage liver disease, variant forms of ESR1 predominates and sometimes becomes the only form expressed [17]. This variant lacks the estrogen-binding domain, but the intact DNAbinding domain maintains constitutive transcriptional activity, plays an important roles in the modulation of cell proliferation and inflammatory processes [36,37]. HBV carriers presenting variant ESR1 have an extremely aggressive clinical course.[13,17] Since variant ESR1 isoform predominates and sometimes becomes the only form expressed in the liver with endstage liver diseases, variant forms of ESR1 may be one of the possible mechanisms underlying the fact that c.453-397 $\mathrm{T}>\mathrm{C}$ genetic variation influences susceptibility to HBV-ALF. our results, that the disease susceptible ESR1 c.453-397 C allele had much stronger transcription activity than c.453-397 $\mathrm{T}$ allele, might suggest the liver failure risked c.453-397 C allele amplifies ESR1 transcription and probably produces more variant ESR1 isoforms compared with c.453-397 T allele. Then patients carrying c.453-397 C allele secret more variant ESR1 and this elevated level of variant ESR1 reduces the response to the action of estrogen, and then risks to HBV-ALF. However, further studies are needed to identify the robust relationship between higher level of variant ESR1 secretion and c.453-397 $\mathrm{T}>\mathrm{C}$ variation in vivo.

\section{Conclusions}

In conclusion, our genetic epidemiological investigation suggests that the c.453-397 $\mathrm{T}>\mathrm{C}$ polymorphism is related to the susceptibility to HBV-related liver failure and could be part of the genetic variations which underlies the phenotypic variation observed in individuals' susceptibility to HBV-ALF in Chinese population. However, our conclusion need be supported by data from other populations. It is also interesting to investigate whether the ESR1 intron region polymorphisms are associated with alcohol and drug induced liver failure in the west countries, where alcohol consumption and drug use are more popular.

\section{Competing interests}

The funding sources had no role in study design, collection, analysis, or interpretation of data, or the writing of the report; or the decision to submit the report for publication. We declare that we have no conflict of interest to disclose.

\section{Acknowledgements}

This work was supported in part by the National Natural Science Foundation of China (Grant No.81 100290), the State Key Project Specialized for Infectious Diseases (2012ZX10002007-002) and Chongqing Natural Science Foundation for Distinguished Young Scholars (grant no. CSTC2011JJJQ1005).

\section{Author details}

${ }^{1}$ Institute of Infectious Diseases, Southwest Hospital Third Military Medical University, Chongqing 400038, P. R. China. ${ }^{2}$ Institute of Immunology Third Military Medical University, Chongqing 400038, P. R. China.

\section{Authors' contributions}

Study design and discussion: ZY, GD, YW; sample collection: ZY, WT, YD, CD; data acquisition: $Z Y, W T, Y D, W Z, C D$; technical support: YD; data analysis and manuscript preparation: $Z Y, G D, W T$; funding: $Z Y, G D$; study supervision: $Y W$,

GD. All authors read and approved the final manuscript.

Received: 23 November 2011 Accepted: 24 June 2012

Published: 24 June 2012

References

1. Polson J, Lee WM: AASLD position paper: the management of acute liver failure. Hepatology 2005, 41:1179-1197.

2. Liu Q, Liu Z, Wang T, Wang Q, Shi X, Dao W: Characteristics of acute and sub-acute liver failure in China: nomination, classification and interval. J Gastroenterol Hepatol 2007, 22:2101-2106.

3. Poynard T, Mathurin P, Lai CL, Guyader D, Poupon R, Tainturier MH, Myers RP, Muntenau M, Ratziu V, Manns M, Vogel A, Capron F, Chedid A, Bedossa $P:$ A comparison of fibrosis progression in chronic liver diseases. J Hepatol 2003, 38:257-265.

4. Shimizu I, Ito S: Protection of estrogens against the progression of chronic liver disease. Hepatol Res 2007, 37:239-247.

5. Shimizu I, Kohno N, Tamaki K, Shono M, Huang HW, He JH, Yao DF: Female hepatology: favorable role of estrogen in chronic liver disease with hepatitis B virus infection. World J Gastroenterol 2007, 13:4295-4305.

6. Shimizu I: Impact of oestrogens on the progression of liver disease. Liver Int 2003, 23:63-69.

7. Nakagawa H, Maeda S, Yoshida H, Tateishi R, Masuzaki R, Ohki T, Hayakawa Y, Kinoshita H, Yamakado M, Kato N, Shiina S, Omata M: Serum IL-6 levels and the risk for hepatocarcinogenesis in chronic hepatitis C patients: an analysis based on gender differences. Int J Cancer 2009, 125:2264-2269.

8. Maeda S: NF-kappaB, JNK, and TLR Signaling Pathways in Hepatocarcinogenesis. Gastroenterol Res Pract 2010, 2010:367694.

9. Ahlbory-Dieker DL, Stride BD, Leder G, Schkoldow J, Trolenberg S, Seidel H, Otto C, Sommer A, Parker MG, Schutz G, Wintermantel TM: DNA binding by estrogen receptor-alpha is essential for the transcriptional response to estrogen in the liver and the uterus. Mol Endocrinol 2009, 23:1544-1555.

10. Rossini GP, Baldini GM, Villa E, Manenti F: Characterization of estrogen receptor from human liver. Gastroenterology 1989, 96:1102-1109.

11. Mizoguchi Y, Takeda H, Sakagami Y, Seki S, Kobayashi K, Yamamoto S, Morisawa S: Estradiol receptors in the cytosol of peripheral blood mononuclear cells in hepatitis B virus carriers treated with interferonalpha. Gastroenterol Jpn 1989, 24:373-379.

12. Codes $L$, Matos $L$, Parana R: Chronic hepatitis $C$ and fibrosis: evidences for possible estrogen benefits. Braz J Infect Dis 2007, 11:371-374.

13. Villa E, Grottola A, Colantoni A, De Maria N, Buttafoco P, Ferretti I, Manenti F: Hepatocellular carcinoma: role of estrogen receptors in the liver. Ann N Y Acad Sci 2002, 963:37-45

14. Giannitrapani L, Soresi M, La Spada E, Cervello M, D'Alessandro N, Montalto G: Sex hormones and risk of liver tumor. Ann N Y Acad Sci 2006, 1089:228-236

15. Villa E, Dugani A, Moles A, Camellini L, Grottola A, Buttafoco P, Merighi A, Ferretti I, Esposito P, Miglioli L, Bagni A, Troisi R, De Hemptinne B, Praet M, Callea F, Manenti F: Variant liver estrogen receptor transcripts already occur at an early stage of chronic liver disease. Hepatology 1998, 27:983-988.

16. Villa E, Camellini L, Dugani A, Zucchi F, Grottola A, Merighi A, Buttafoco P, Losi L, Manenti F: Variant estrogen receptor messenger RNA species detected in human primary hepatocellular carcinoma. Cancer Res 1995, 55:498-500

17. Villa E, Colantoni A, Grottola A, Ferretti I, Buttafoco P, Bertani H, De Maria N, Manenti F: Variant estrogen receptors and their role in liver disease. $\mathrm{Mol}$ Cell Endocrinol 2002, 193:65-69.

18. Figtree GA, Noonan JE, Bhindi R, Collins P: Estrogen receptor polymorphisms: significance to human physiology, disease and therapy. Recent Pat DNA Gene Seq 2009, 3:164-171.

19. Deng G, Zhou G, Zhai Y, Li S, Li X, Li Y, Zhang R, Yao Z, Shen Y, Qiang B, Wang Y, He F: Association of estrogen receptor alpha polymorphisms with susceptibility to chronic hepatitis B virus infection. Hepatology 2004, 40:318-326.

20. Yan Z, Tan W, Xu B, Dan Y, Zhao W, Deng C, Chen W, Tan S, Mao Q, Wang $Y$, Deng G: A cis-acting regulatory variation of the estrogen receptor 
alpha (ESR1) gene is associated with hepatitis B virus-related liver cirrhosis. Hum Mutat 2011, 32:1128-1136.

21. Zhai Y, Zhou G, Deng G, Xie W, Dong X, Zhang X, Yu L, Yang H, Yuan X, Zhang H, Zhi L, Yao Z, Shen Y, Qiang B, He F: Estrogen receptor alpha polymorphisms associated with susceptibility to hepatocellular carcinoma in hepatitis B virus carriers. Gastroenterology 2006, 130:2001-2009.

22. Yan Z, Tan W, Zhao W, Dan Y, Wang X, Mao Q, Wang Y, Deng G: Regulatory polymorphisms in the IL-10 gene promoter and HBV-related acute liver failure in the Chinese population. J Viral Hepat 2009, 16:775-783.

23. den Dunnen JT, Antonarakis SE: Nomenclature for the description of human sequence variations. Hum Genet 2001, 109:121-124.

24. Ogino S, Gulley ML, den Dunnen JT, Wilson RB: Standard mutation nomenclature in molecular diagnostics: practical and educational challenges. J Mol Diagn 2007, 9:1-6.

25. Stephens M, Smith NJ, Donnelly P: A new statistical method for haplotype reconstruction from population data. Am J Hum Genet 2001, 68:978-989.

26. Ding K, Zhou K, He F, Shen Y: LDA-a java-based linkage disequilibrium analyzer. Bioinformatics 2003, 19:2147-2148.

27. Thursz M: Pros and cons of genetic association studies in hepatitis B. Hepatology 2004, 40:284-286.

28. Manly KF: Reliability of statistical associations between genes and disease. Immunogenetics 2005, 57:549-558.

29. Wacholder S, Chanock S, Garcia-Closas M: El Ghormli L, Rothman N Assessing the probability that a positive report is false: an approach for molecular epidemiology studies. J Natl Cancer Inst 2004, 96:434-442.

30. Einarsdottir K, Darabi H, Li Y, Low YL, Li YQ, Bonnard C, Sjolander A, Czene K, Wedren S, Liu ET, Hall P, Humphreys K, Liu J: ESR1 and EGF genetic variation in relation to breast cancer risk and survival. Breast Cancer Res 2008, 10:R15.

31. Siddig A, Mohamed AO, Awad S, Hassan AH, Zilahi E, Al-Haj M, Bernsen R, Adem A: Estrogen receptor alpha gene polymorphism and breast cancer. Ann N Y Acad Sci 2008, 1138:95-107.

32. Wise BL, Demissie S, Cupples LA, Felson DT, Yang M, Shearman AM, Aliabadi $P$, Hunter DJ: The relationship of estrogen receptor-alpha and -beta genes with osteoarthritis of the hand. J Rheumatol 2009, 36:2772-2779.

33. Lawlor DA, Timpson N, Ebrahim S, Day IN, Smith GD: The association of oestrogen receptor alpha-haplotypes with cardiovascular risk factors in the British Women's Heart and Health Study. Eur Heart J 2006 27:1597-1604.

34. Joshi G, Pradhan S, Mittal B: Role of the oestrogen receptor (ESR1 Pvull and ESR1 $325 \mathrm{C}->\mathrm{G}$ ) and progesterone receptor (PROGINS) polymorphisms in genetic susceptibility to migraine in a North Indian population. Cephalalgia 2010, 30:311-320

35. Yeh SH, Chen PJ: Gender disparity of hepatocellular carcinoma: the roles of sex hormones. Oncology 2010, 78(Suppl 1):172-179.

36. Alvaro D, Alpini G, Onori P, Perego L, Svegliata Baroni G, Franchitto A, Baiocchi L, Glaser SS, Le Sage G, Folli F, Gaudio E: Estrogens stimulate proliferation of intrahepatic biliary epithelium in rats. Gastroenterology 2000, 119:1681-1691

37. Kassi E, Moutsatsou P: Estrogen receptor signaling and its relationship to cytokines in systemic lupus erythematosus. J Biomed Biotechnol 2010, 2010:317452.

doi:10.1186/1471-2350-13-49

Cite this article as: Yan et al.: Estrogen receptor alpha gene polymorphisms and risk of HBV-related acute liver failure in the Chinese population. BMC Medical Genetics 2012 13:49.

\section{Submit your next manuscript to BioMed Central and take full advantage of:}

- Convenient online submission

- Thorough peer review

- No space constraints or color figure charges

- Immediate publication on acceptance

- Inclusion in PubMed, CAS, Scopus and Google Scholar

- Research which is freely available for redistribution

Submit your manuscript at www.biomedcentral.com/submit
Biomed Central 